\title{
Vitamin D Levels and Depressive Symptoms' Severity Among University Employees in Lebanon
}

\author{
Doris Jaalouk ${ }^{1}$, Jocelyne Boumosleh ${ }^{1} \&$ Mira Fatayri $^{1}$ \\ ${ }^{1}$ Department of Nursing and Health Sciences, Notre Dame University-Louaize, Zouk Mosbeh, Lebanon \\ Correspondence: Doris Jaalouk, Faculty of Nursing \& Health Sciences, Notre Dame University-Louaize, P.O.Box: \\ 72 Zouk Mikael, Zouk Mosbeh, Lebanon. Tel: 1-961-921-8950. E-mail: djaalouk@ndu.edu.lb
}

Received: March 19, 2018 Accepted: April 14, 2018 Online Published: April 23, 2018

doi:10.5539/gjhs.v10n6p21 URL: https://doi.org/10.5539/gjhs.v10n6p21

\begin{abstract}
Background: Despite the evidence that the association between serum vitamin D level and susceptibility to depression is altered by ethnicity and vitamin $\mathrm{D}$ receptor gene polymorphisms, high prevalence of vitamin $\mathrm{D}$ deficiency, and parallel substantial burden of depression among Middle Eastern/ Arab adult populations, research exploring whether low serum vitamin D level is associated with increased risk of depression among Arab adult populations is almost non-existent.
\end{abstract}

Objective: This study aims to investigate the relationship between serum vitamin D levels and severity of depressive symptoms among a sample of healthy Lebanese adults, controlling for multiple confounders.

Methods: A total of 351 employees at a private university in Lebanon were surveyed. Information about sociodemographic, lifestyle habits, medical/ family history; and depressive symptoms were collected using a background questionnaire, international physical activity questionnaire -short form, and Patient Health Questionnaire, respectively. Anthropometric measurements and fasting blood samples were collected using standard methods. Serum 25-hydroxyvitamin D [25(OH)D] levels were measured by means of ELISA. Multiple linear regression analyses were conducted. A p-value of less than 0.05 was considered statistically significant.

Results: Sample mean age was 42.36 years. In the fully adjusted model, higher depression scores were found to be border-line significantly $(\mathrm{p}=0.058)$ associated with lower serum $25-(\mathrm{OH}) \mathrm{D}$ levels and significantly associated with younger age, female sex, lower income, chronic illness diagnosis, family history of mental illness, number of stressful life events, and intake of antidepressants.

Conclusion: We did not find any significant independent association between serum 25(OH)D levels and severity of depressive symptoms in a sample of Lebanese employees of a private university.

Keywords: serum 25-hydroxyvitamin D [25(OH)D], depressive symptoms, healthy employees

\section{Introduction}

The relationship between vitamin $\mathrm{D}$ and depression in the general adult population has come under scrutiny by many investigators worldwide owing to research reports revealing high prevalence of vitamin D deficiency (Arabi, El Rassi, \& El-Hajj Fuleihan, 2010; Holick \& Chen, 2008), presence of vitamin D receptors in areas of the brain involved in mood regulation (Eyles, Liu, Josh, \& Cui, 2014; Eyles, Smith, Kinobe, Hewison, \& McGrath, 2005) and the high burden of depression/ depressive disorders in the general adult population (World health Organization, 2017). Findings from systematic reviews and meta-analyses of observational studies have not been consistent. While one meta-analysis of 9 cross-sectional studies found an increased, though non-significant, adjusted odds ratio (OR) of depression for the lowest versus the highest vitamin $\mathrm{D}$ categories $(\mathrm{OR}=1.31,95 \%$ CI $1.00-1.71$, $\mathrm{p}=0.05$ ) (Anglin et al., 2013), a second meta-analysis of 11 cross-sectional studies arrived at a pooled estimate of adjusted ORs of depression of 0.96 for a $10 \mathrm{ng} / \mathrm{ml}$ increase in $25(\mathrm{OH}) \mathrm{D}$ levels $(95 \% \mathrm{CI}=0.94-0.99$, p $=0.003)(\mathrm{Ju}$ et al., 2013). Summary estimates from three meta-analyses of the same 3 cohort studies suggested a borderline statistically significant inverse association between serum vitamin D levels and depression; whereas estimate obtained from a fourth meta-analysis of the same 3 cohort studies did not reveal an association (Anglin et al., 2013). Another meta-analysis of 5 cohort studies showed a non-significant association between serum vitamin D levels and depression; the pooled adjusted OR of depression for a $10 \mathrm{ng} / \mathrm{ml}$ increase in $25(\mathrm{OH}) \mathrm{D}$ levels was found to be $0.92(95 \% \mathrm{CI}=0.87-0.98, \mathrm{p}=0.090)(\mathrm{Ju}$ et al., 2013). Moreover, findings from systematic reviews and 
meta-analyses of randomized controlled trials (RCTs) which tested the effect of vitamin D supplementation on depression revealed no overall significant effect of vitamin D supplementation ( $\mathrm{Li}$ et al., 2014; Shafffer et al., 2014). Results from individual RCTs were inconsistent and were partly accounted for by methodological limitations (comparison groups, baseline serum 25(OH)D level of study groups, baseline depressive symptoms of study groups, and variations in vitamin D supplementation protocol). Investigators noted that vitamin D supplementation is likely to be effective in reducing depressive symptoms in subjects with clinically significant depressive symptoms or depressive disorder (Li et al., 2014; Shaffer et al., 2014; Spedding et al., 2014).

Several studies revealed that the association between serum vitamin D level and susceptibility to disease (cancer, diabetes type 2, autoimmune diseases, depression, etc.) is altered by ethnicity and vitamin D receptor (VDR) gene polymorphisms (VDR genetic variants) of the studied population (Abdollahzadeh, et al., 2016; Kuningas, et al., 2009; Shaikh, Baig, \& Jamal, 2016; Yu, et al., 2016). Despite published reports revealing high prevalence of vitamin D deficiency (Arabi et al. 2010; Bassil, Rahme, Hoteit, \& Fuleihan, 2013; Fuleihan, et al., 2015), and parallel substantial burden of depression (Charara et al., 2017; Karam, et al., 2008; Mokdad, 2017) among Middle Eastern/ Arab adult populations, including Lebanon, research exploring whether low serum vitamin D level is associated with increased risk of depression or severity of depressive symptoms among Arab adult samples is almost non-existent. This study aims to investigate the relationship between serum vitamin D levels and severity of depressive symptoms among a sample of healthy Lebanese adults.

\section{Methods}

\subsection{Study Design}

This study used a cross-sectional research design and was conducted in a sample of employees (faculty members, administrators, and staff) of Notre Dame University (NDU), Lebanon between October and December 2016.

\subsection{Recruitment and Data Collection Methods}

Researchers sent an email to all NDU employees to inform them about the study purpose and solicit their participation in the study. Following the e-invitation, trained graduate research assistants (GRAs) arranged appointments with all faculty members, administrators and staff, and visited them in their offices to elaborate on the study objectives, confirm their interest in participation and clarify any existing study-related inquiries. Employees who expressed an interest in enrollment were then screened for eligibility; exclusion criteria were: pregnant and lactating women, and individuals with a pacemaker or a metal piece in the body. Those who were found to be eligible were then asked to read and sign a consent form. After completion of the consenting process, study participants were either interviewed by the GRA during the visit or contacted by the study investigators to arrange an interview appointment with a GRA, for about 30 minutes in the participant's office. At the beginning of the interview, the GRA assigned a numeric code to each participant and then filled out four questionnaires (Background Questionnaire, International Physical Activity Questionnaire - Short Form (IPAQ-SF), Food Frequency Questionnaire (FFQ) for vitamin D intake assessment and the Patient Health Questionnaire-9 (PHQ-9)) based on the participant's responses . All questionnaires were pre-tested using a random sample of thirty NDU employees. Revisions and corrections were done before initiating the study. At the end of the interview, GRAs scheduled appointments with participants for anthropometric measurements (body weight, height, and waist circumference (WC), body composition) and a fasting blood sample draw at the Nutrition Research Lab, Department of Nursing and Health Sciences. Participants were instructed to fast for at least 8 hours prior to their research lab morning appointment. The file linking the participants' names with their codes was password-protected and saved on the principal investigator (PI)'s computer.

\subsection{Measures}

\subsubsection{Sociodemographic, Lifestyle Habits, and Medical History Data}

We developed a questionnaire (Background Questionnaire) to collect data on sociodemographic variables (age, sex, educational level, income, marital status), lifestyle habits (smoking, alcohol drinking, daily sun exposure, and sunscreen use), recent medical history (diagnosis with chronic illnesses- any of cardiovascular diseases, diabetes, asthma, liver disease, kidney disease, thyroid gland disorders, neurological diseases, cancer, mental illness diagnosis; intake of medications including antidepressants), family history of mental illness, and stressful life events during the past year.

\subsubsection{Physical Activity Level}

We used the International Physical Activity Questionnaire - Short Form (IPAQ-SF) to measure level of physical activity among study participants. IPAQ-SF assesses total minutes of walking, moderate and vigorous intensity 
activity in the last week. Participants' levels of physical activity were categorized as follows: low (MET-minutes per week $<600)$, moderate $(600 \leq$ MET-minutes per week $<3000)$, and high (MET-minutes per week $\geq 3000)$ (Booth, 2000).

\subsubsection{Dietary Intake of Vitamin D}

We used an adapted version of a Food Frequency Questionnaire (FFQ) prototype, developed by study investigators, for assessment of intake (consumption frequency, number of servings, and average portion size) of vitamin D- rich foods and supplements during the past month (El Hayek et al., 2014). Nutritionist Pro diet analysis software, the Middle-East Food Composition Tables (Pellett \& Shadarevian, 2013), and the Canadian Nutrient File (Government of Canada, 2017) were used to generate estimates of dietary intake of vitamin D.

\subsubsection{Depressive Symptoms' Severity}

We used the Patient Health Questionnaire-9 (PHQ-9) to determine depressive symptoms' severity (Kroenke, Spitzer, Williams, \& Löwe, 2010). PHQ-9 is a nine-item self- reported depression questionnaire which scores each of the 9 DSM IV- items as " 0 " (not at all) to " 3 "(nearly every day), giving a total severity score of 0 to 27 . Higher PHQ-9 scores indicate more severe depressive symptoms, with threshold scores of 5, 10, 15, and 20 or higher indicating mild, moderate, moderately severe and severe depression (Pfizer, 2016), respectively.

\subsubsection{Anthropometric Measurements}

Body weight and height of participants were measured without shoes and wearing light clothes to the nearest 0.1 $\mathrm{kg}$ and $0.1 \mathrm{~cm}$ and using a digital scale and portable stadiometer, respectively. Body mass index (BMI) was calculated as weight in kilograms $(\mathrm{kg})$ divided by height in meters squared $\left(\mathrm{m}^{2}\right)$. Weight status was determined as follows: underweight $(\mathrm{BMI}<18.5)$, normal weight $(\mathrm{BMI}=18.5-24.9)$, overweight $(\mathrm{BMI}=25.0-29.9)$, or obese $(B M I \geq 30.0)$ (WHO Expert Consultation, 2004). Waist circumference (WC) was measured just above the iliac crest at the midaxillary line with a measuring tape at the end of normal expiration to the nearest $0.1 \mathrm{~cm}$. WC value $>$ $102 \mathrm{~cm}$ in men and $>88 \mathrm{~cm}$ in women is considered an indicator of increased cardio-metabolic disease risk (CDC, 2007).

\subsubsection{Serum 25(OH)D Level and Other Biochemical Measurements}

Upon the visit to the Research Nutrition Lab, a nurse collected a fasting blood sample from study participants. Blood fractionation by centrifugation for 15 minutes at a speed of $1,800 \mathrm{rpm}$ occurred at site of blood withdrawal within 2 hours of collecting blood samples. After fractionation, serum was pipetted into separate tubes while the other components of blood were discarded. Serum samples were stored at $-20^{\circ} \mathrm{C}$ for a maximum period of 6 weeks before analysis. Serum 25(OH)D levels were measured using enzyme linked immunosorbent assay (ELISA) kit (from Calbiotech, Inc, USA), The inter-assay coefficient of variation (CV) was $5.63 \%$, and the intra-assay CV was $4.95 \%$. Vitamin D status was assessed according to Institute of Medicine (IOM) and Endocrine Society (ES). IOM considers subjects with serum 25(OH)D levels $\leq 10 \mathrm{ng} / \mathrm{ml}$ deficient, $>10-20 \mathrm{ng} / \mathrm{ml}$ insufficient and $>20 \mathrm{ng} / \mathrm{ml}$ sufficient (Ross, Taylor, Yaktine, \& Del Valle, 2011). However, ES considers subjects with serum 25(OH)D levels $\leq 20 \mathrm{ng} / \mathrm{ml}$ deficient, $>20-30 \mathrm{ng} / \mathrm{ml}$ insufficient and $>30 \mathrm{ng} / \mathrm{ml}$ sufficient (Holick et al., 2011).

\subsection{Statistical Analyses}

Assuming that the prevalence rate of moderate-severe depression among community-dwelling general adult population in Lebanon is about 10\% (Karam et al., 2008), the sample size was calculated and found to be 138 individuals. Data were entered, the data file was checked for errors and errors were corrected before data analysis. Continuous variables were summarized as mean \pm standard deviation/median (interquartile range), whereas categorical variables were summarized as $\mathrm{n}(\%)$. Mean values of continuous variables for independent groups were compared using independent sample T Test/Mann-Whitney-U-test/Analysis of variance.

Multiple linear regression analysis was used to assess the independent association between serum 25(OH)D levels and severity of depressive symptoms (PHQ-9 score). Preliminary analyses were conducted to ensure no violation of the assumptions of normality, linearity, multicollinearity and homoscedasticity. Normality of the variables was assessed and $\log$ transformations were performed. The correlation between each of the independent variables included in the regression models and tolerance/VIF values were examined to pick up problems with multicollinearity (Tolerance $<0.1$, VIF $>10$ ). Normality of the residuals was assessed by inspecting the normal probability plot of the regression standardized residual and the residuals scatterplot.

Model 1 was unadjusted, showing the main effect of serum 25(OH)D levels (independent variable) on severity of depressive symptoms (dependent variable); model 2 was adjusted for socio-demographic characteristics (age, sex, income, and marital status) and BMI; model 3 was additionally adjusted for lifestyle habits (smoking, alcohol 
drinking and physical activity). Model 4 was our fully adjusted model in which socio-demographics, lifestyle habits, and physical and mental health- related variables (chronic illness diagnosis, other mental illness diagnosis, family history of mental illness, number of stressful life events, and intake of antidepressants) were controlled for. Data were analyzed using the Statistical Package for Social Sciences (SPSS) version 22 for Windows. P-values of less than 0.05 were regarded as statistically significant.

\subsection{Ethical Approval}

The study protocol was approved by the Institutional Review Board at NDU. All participants signed informed consent prior to data collection.

\section{Results}

\subsection{Sample Characteristics}

The sample consisted of 351 NDU faculty and staff members (49\% men and $51 \%$ women) with a mean age of $42.36 \pm 11.52$ years. The majority of the study participants reported to be married $(\sim 66 \%)$, live in urban areas $(61 \%)$, have a university degree or its equivalent $(\sim 79 \%)$ with a monthly income of at least $\$ 2,250(\sim 68 \%)$. With regard to disease risk, a substantial percentage of the surveyed participants were found to have risk factors for disease including overweight/obesity ( 64\%), risky waist circumference (as per description in section 2.3.5) ( $51 \%$ ), low physical activity levels (65\%), smoking (38\%), vitamin D inadequacy (IOM: $\leq 20 \mathrm{ng} / \mathrm{ml} ; \mathrm{ES}: \leq 30$ $\mathrm{ng} / \mathrm{ml}$ ) (IOM: 32\%- 38\%; ES:63\%-73\%, without and with excluding those taking vitamin D supplement, respectively), with about $41 \%$ reporting to have had a recent diagnosis with a chronic disease. In addition, about $29 \%$ of the study participants were found to have depression symptoms, after excluding those taking antidepressants (Table 1).

Table 1. Sample characteristics: sociodemographic, anthropometric, and lifestyle factors, serum 25-(OH)D levels, and depressive symptoms' severity $(\mathrm{n}=351)$

\begin{tabular}{llll}
\hline & $\begin{array}{l}\text { Mean } \pm \text { SD } \\
\text { Or n (\%) }\end{array}$ & & $\begin{array}{l}\text { Mean } \pm \text { SD } \\
\text { Or n (\%) }\end{array}$ \\
\hline Age (years) & $42.36 \pm 11.52$ & Sunscreen use & \\
Sex & & No & $249(70.9)$ \\
Male & $172(49)$ & Yes & $102(29.1)$ \\
Female & $179(51)$ & Smoking & \\
Residence & & No & $218(62.1)$ \\
Urban & $214(61)$ & Yes & $133(37.9)$ \\
Rural & $137(39)$ & Alcohol drinking & \\
Marital status & & No & $261(74.4)$ \\
Single, separated, divorced & $119(33.9)$ & Yes & $90(25.6)$ \\
Married & $232(66.1)$ & Physical activity level & \\
Income (monthly) (\$) & & Low & $227(64.7)$ \\
$<1,250$ & $31(8.8)$ & Moderate & $113(32.2)$ \\
$1,250-2,250$ & $83(23.6)$ & High & $11(3.1)$ \\
$2,250-4,000$ & $88(25.1)$ & Chronic illness diagnosis & \\
$4,000-5,333$ & $70(19.9)$ & No & $207(59.1)$ \\
$>5,333$ & $79(22.5)$ & Yes & $143(40.9)$ \\
Education level & & $\mathbf{2 5 ( O H ) D ~ l e v e l ~ ( n g / m l ) ~ ( n = 3 4 8 ) ~}$ & $28.15 \pm 13.93$ \\
High school & $75(21.4)$ & $\mathbf{2 5 ( O H ) D ~ s t a t u s ~}$ & $16(4.6)$ \\
Bachelor & $90(25.6)$ & $\leq 10$ ng/ml & $95(27.3)$ \\
Graduate & $186(53.0)$ & $>10$ to $\leq 20$ ng/ml & $108(31.0)$ \\
BMI & & $>20$ to $\leq 30 \mathrm{ng} / \mathrm{ml}$ &
\end{tabular}




\begin{tabular}{llll}
\hline Underweight & $3(0.9)$ & $>30 \mathrm{ng} / \mathrm{ml}$ & $129(37.1)$ \\
Normal & $124(35.3)$ & Depressive symptoms severity ${ }^{1}(\mathrm{n}=335)$ & $239(71.3)$ \\
Overweight & $133(37.9)$ & None & $78(23.3)$ \\
Obese & $91(25.9)$ & Mild & $18(5.4)$ \\
WC & & Moderate- severe & \\
Normal & $173(49.3)$ & & \\
Risky & $178(50.7)$ & \\
Intake of vitamin D supplement & & \\
past 3 mo & & \\
No & $276(78.6)$ & \\
Yes & $75(21.4)$ & \\
Daily exposure to direct sunlight & & \\
5 min or less & $57(16.2)$ & \\
$5-15$ min & $81(23.1)$ & \\
$16-30$ min & $65(18.5)$ & \\
$31-60$ min & $51(14.5)$ & \\
More than 1 hour & $97(27.6)$ & \\
\hline
\end{tabular}

${ }^{1}$ Excluding subjects taking antidepressant medication $(n=16)$.

3.2 Associations of Sociodemographic, Anthropometric \& Lifestyle Factors With Serum 25-Hydroxyvitamin D Levels

Lower serum 25(OH)D levels were found to be associated with lack of vitamin D supplementation (no: $25.52 \pm 12.51$; yes: $37.86 \pm 14.69, \mathrm{p}=0.000$ ), risky waist circumference (risky: $26.40 \pm 13.67$; healthy: $29.91 \pm 14.01$, $\mathrm{p}=0.010$ ) and low/moderate physical activity levels (low: $27.59 \pm 14.20$; moderate: $27.92 \pm 11.89$; high: $41.92 \pm 20.86$, $\mathrm{p}=0.042$ ) (Table 2). Furthermore, lower $25(\mathrm{OH}) \mathrm{D}$ levels were found to be significantly correlated with lower vitamin $\mathrm{D}$ intake from food $(\mathrm{r}=0.181, \mathrm{p}=0.001)$ (Data not shown).

Table 2. Associations of sociodemographic, anthropometric, and lifestyle factors with serum 25-(OH)D level $(\mathrm{n}=351)$

\begin{tabular}{llc}
\hline & Mean \pm SD & Pvalue \\
\hline Age (years) & & 0.271 \\
$\leq 36$ & $26.63 \pm 12.92$ & \\
$37-48$ & $29.04 \pm 14.27$ & 0.737 \\
$\geq 49$ & $28.90 \pm 14.61$ & \\
Sex & & 0.328 \\
Male & $28.38 \pm 15.01$ & \\
Female & $27.92 \pm 12.84$ & \\
Income (monthly) (\$) & & \\
$<\quad 1,250$ & $30.47 \pm 14.73$ & \\
$1,250-2,250$ & $26.27 \pm 14.71$ & \\
$2,250-4,000$ & $27.24 \pm 13.11$ & \\
$4,000-5,333$ & $28.41 \pm 13.74$ & \\
$>5,333$ & $30.02 \pm 13.83$ & \\
\hline
\end{tabular}


Education level

High school

Bachelor degree

Graduate

Residence

Urban

Rural

Daily exposure to direct sunlight

5 min or less

5-15 $\mathrm{min}$

16-30 $\mathrm{min}$

31-60 min

More than 1 hour

\section{Sunscreen use}

No

yes

Intake of vitamin D supplement past 3 mo

No

Yes

BMI excluding underweight (3 participants)

Normal

Overweight

Obese

WC

Normal

Risky

Chronic illness diagnosis

No

Yes

Smoking

No

Yes

Alcohol drinking

No

Yes

Physical activity level

Low

Moderate

High

Depressive symptoms' severity ${ }^{1}$

None

Mild

Moderate-severe

\subsection{1}

$26.99 \pm 14.32$

$28.13 \pm 14.10$

$28.61 \pm 13.74$

$28.58 \pm 14.13$

$27.47 \pm 13.63$

$27.15 \pm 14.20$

$29.21 \pm 14.76$

$25.78 \pm 11.11$

$26.78 \pm 11.26$

$30.09 \pm 15.74$

0.071

$27.57 \pm 14.39$

$29.53 \pm 12.72$

0.000

$25.52 \pm 12.51$

$37.86 \pm 14.69$

$29.27 \pm 14.22$

$27.93 \pm 13.34$

$26.23 \pm 13.78$

0.010

$29.91 \pm 14.01$

$26.40 \pm 13.67$

0.468

$27.61 \pm 13.33$

$28.96 \pm 14.82$

0.093

$27.35 \pm 13.89$

$29.45 \pm 13.95$

$27.35 \pm 13.88$

$30.42 \pm 13.91$

0.042

$27.59 \pm 14.20$

$27.92 \pm 11.89$

$41.92 \pm 20.86$

$28.66 \pm 14.06$

$26.82 \pm 14.18$

$24.17 \pm 9.52$

${ }^{1}$ Excluding subjects taking antidepressant medication $(n=16)$. 


\subsection{Association of serum 25-hydroxyvitamin D levels With Depression Score (PHQ-9 Score)}

Multiple linear regression models were used to assess the ability of serum 25(OH)D levels to predict severity of depression symptoms, after controlling for the influence of confounding variables. In the unadjusted model (Model 1), higher depression scores (PHQ-9 scores) were found to be borderline significantly associated with lower serum 25(OH)D levels ( $\mathrm{p}=0.054$ ), whereby PHQ-9 score increases by about 0.003 units for a $1 \mathrm{ng} / \mathrm{ml}$ decrease in serum vitamin D levels, and with serum vitamin D levels explaining about $1 \%$ of the variance in PHQ-9 scores. This borderline association vanished upon entry of variables that represent personal characteristics (age, sex, BMI, income and marital status) into the model (Model 2); entry of these variables increased the variance in PHQ-9 scores explained by the independent variables (serum vitamin D levels, age, sex, BMI, income and marital status) to about $10 \%$. Entry of the independent variables that pertain to lifestyle habits (smoking, alcohol drinking and physical activity) into the model (Model 3) only increased the total variance explained by the independent variables (serum vitamin D levels, age, sex, BMI, income, marital status, smoking, alcohol drinking and physical activity) by about $1 \%$. After additional entry of variables that represent physical/mental health into the model (Model 4), the total variance explained by the independent variables (serum vitamin D levels, age, sex, BMI, income, marital status, smoking, alcohol drinking, physical activity, chronic illness diagnosis, other mental illness diagnosis, family history of mental illness, number of stressful life events, and intake of antidepressants) increased to about $19 \%$. In the final model (Model 4), higher depression scores were found to be borderline significantly associated with lower serum vitamin $\mathrm{D}$ levels $(\beta=-0.110, \mathrm{p}=0.058)$ and significantly associated with younger age, female sex, lower income, chronic illness diagnosis, family history of mental illness, number of stressful life events, and intake of antidepressants, with age recording the highest beta value $(\beta=-0.201, p=0.004)$ followed by income $(\beta=-0.171, p=0.004)$, sex $(\beta=0.165, p=0.009)$, intake of antidepressants $(\beta=0.157, p=0.013)$, chronic illness diagnosis $(\beta=0.140, p=0.027)$, number of stressful life events $(\beta=0.130, p=0.024)$, and family history of mental illness $(\beta=0.127, p=0.027)$. Specifically, after controlling for all other variables in the model, severity of depression symptoms score (PHQ-9 score) increases by 0.003 unit for a $1 \mathrm{ng} / \mathrm{ml}$ decrease in serum 25-OHD levels, by 0.006 unit for a 1 year decrease in age, and by 0.042 unit for a 1 dollar decrease in income. In addition, females, individuals who have a chronic illness, family history of mental illness, have an additional stressful life event and take antidepressants were found to have a 0.105, 0.090, 0.162, 0.053 and 0.238- unit higher PHQ-9 score (Table 3).

Table 3. Association between serum 25(OH)D level and depressive symptoms' severity score, as assessed by multiple linear regression*

\begin{tabular}{|c|c|c|c|c|c|c|c|}
\hline & \multirow{3}{*}{$\begin{array}{l}\text { Unstandardized } \\
\beta\end{array}$} & \multirow{3}{*}{ S.E. } & \multirow{3}{*}{$\begin{array}{l}\text { Standardized } \\
\beta\end{array}$} & \multirow{3}{*}{ p-value } & \multirow{2}{*}{\multicolumn{2}{|c|}{$\begin{array}{l}\text { 95\% CI for unstandardized } \\
\beta\end{array}$}} & \multirow{3}{*}{$\begin{array}{l}\mathbf{R} \\
\text { square }\end{array}$} \\
\hline & & & & & & & \\
\hline & & & & & $\begin{array}{l}\text { Lower } \\
\text { Boundary }\end{array}$ & $\begin{array}{l}\text { Upper } \\
\text { Boundary }\end{array}$ & \\
\hline Model 1 & & & & & & & 0.013 \\
\hline Serum $25(\mathrm{OH})$ D level & -0.003 & 0.001 & -0.115 & 0.054 & -0.005 & 0.000 & \\
\hline Model 2 & & & & & & & 0.102 \\
\hline Serum 25(OH)D level & -0.002 & 0.001 & -0.091 & 0.123 & -0.005 & 0.001 & \\
\hline Age & -0.004 & 0.002 & -0.130 & 0.048 & -0.007 & 0.000 & \\
\hline Sex & 0.120 & 0.039 & 0.189 & 0.003 & 0.042 & 0.197 & \\
\hline BMI & 0.000 & 0.004 & 0.008 & 0.905 & -0.008 & 0.009 & \\
\hline Income & -0.039 & 0.015 & -0.156 & 0.008 & -0.067 & -0.010 & \\
\hline Marital status & 0.011 & 0.042 & 0.016 & 0.795 & -0.071 & 0.093 & \\
\hline Model 3 & & & & & & & 0.108 \\
\hline Serum 25(OH)D level & -0.002 & 0.001 & -0.101 & 0.092 & -0.005 & 0.000 & \\
\hline Age & -0.004 & 0.002 & -0.131 & 0.048 & -0.007 & 0.000 & \\
\hline Sex & 0.133 & 0.041 & 0.209 & 0.001 & 0.052 & 0.213 & \\
\hline BMI & 0.001 & 0.004 & 0.018 & 0.783 & -0.007 & 0.009 & \\
\hline Income & -0.040 & 0.015 & -0.163 & 0.007 & -0.070 & -0.011 & \\
\hline Marital status & 0.012 & 0.042 & 0.018 & 0.776 & -0.071 & 0.095 & \\
\hline
\end{tabular}




\begin{tabular}{lllllll}
\hline Smoking & 0.007 & 0.040 & 0.011 & 0.863 & -0.072 & 0.086 \\
Alcohol drinking & 0.025 & 0.044 & 0.034 & 0.577 & -0.062 & 0.111 \\
Physical activity & 0.043 & 0.034 & 0.074 & 0.212 & -0.025 & 0.110 \\
\hline Model 4 & & & & & & \\
Serum 25(OH)D level & -0.003 & 0.001 & -0.110 & 0.058 & -0.005 & 0.000 \\
Age & -0.006 & 0.002 & -0.201 & 0.004 & -0.009 & -0.002 \\
Sex & 0.105 & 0.040 & 0.165 & 0.009 & 0.026 & 0.184 \\
BMI & -0.001 & 0.004 & -0.023 & 0.716 & -0.010 & 0.007 \\
Income & -0.042 & 0.015 & -0.171 & 0.004 & -0.071 & -0.014 \\
Marital status & 0.015 & 0.041 & 0.023 & 0.708 & -0.065 & 0.096 \\
Smoking & -0.002 & 0.039 & -0.003 & 0.964 & -0.078 & 0.074 \\
Alcohol drinking & 0.027 & 0.043 & 0.037 & 0.529 & -0.057 & 0.111 \\
$\begin{array}{l}\text { Physical activity } \\
\text { Chronic illness }\end{array}$ & 0.042 & 0.033 & 0.073 & 0.202 & -0.023 & 0.107 \\
diagnosis & 0.090 & 0.041 & 0.140 & 0.027 & 0.010 & 0.171 \\
$\begin{array}{l}\text { Other mental illness } \\
\text { diagnosis }\end{array}$ & -0.090 & 0.114 & -0.049 & 0.431 & -0.314 & 0.135 \\
$\begin{array}{l}\text { Family history of } \\
\text { mental illness }\end{array}$ & 0.162 & 0.073 & 0.127 & 0.027 & 0.019 & 0.306 \\
$\begin{array}{l}\text { Number of stressful } \\
\text { life events }\end{array}$ & 0.053 & 0.023 & 0.130 & 0.024 & 0.007 & 0.099 \\
$\begin{array}{l}\text { Intake of } \\
\text { antidepressants }\end{array}$ & 0.238 & 0.096 & 0.157 & 0.013 & 0.050 & 0.427 \\
\hline
\end{tabular}

* Dependent Variable: Depressive symptoms' severity score (log total PHQ-9 score).

\section{Discussion}

To repeat, our study aimed to explore whether serum $25(\mathrm{OH}) \mathrm{D}$ levels are related to depressive symptoms among a sample of apparently healthy adults from Lebanon adjusting for multiple confounders. We targeted a group of employees of a private university in Lebanon aged 20 to 65 years during late fall season (November-December). Mean serum 25(OH)D levels of the study participants was found to be $28.15 \pm 13.93 \mathrm{ng} / \mathrm{ml}$, and close to $32 \%$ had vitamin D deficiency as per ES criteria $25(\mathrm{OH}) \mathrm{D}$ levels $\leq 20 \mathrm{ng} / \mathrm{ml}$. Just $5.4 \%$ of the total sample reported moderate to severe symptoms of depression, as determined by PHQ-9 scores. Findings from multiple linear regression analyses revealed no statistically significant association between serum 25(OH)D levels and severity of depressive symptoms in our sample, before and after adjustment for sociodemographic, and lifestyle factors, BMI, presence of current chronic medical conditions and other mental illness, family history of mental illness, and current stressful events.

Our sample mean serum 25(OH)D level $(28.15 \pm 13.93 \mathrm{ng} / \mathrm{ml})$ was higher and prevalence rate of vitamin D deficiency $(\leq 20 \mathrm{ng} / \mathrm{ml})(32 \%)$ were lower than those reported in two studies involving samples of healthy Lebanese adults (Gannagé-Yared et al., 2014; Malaeb, Hallit, \& Salameh, 2017); this could be attributed to differences in characteristics among study samples. Mean serum 25(OH)D level was found to be $15.61 \pm 7.91$ $\mathrm{ng} / \mathrm{ml}$ and prevalence rate of vitamin D deficiency $(<20 \mathrm{ng} / \mathrm{ml})$ was reported at $71.4 \%$ among a sample of 392 healthy private hospital employees (nurses, medical assistants, technicians, secretaries, medical engineers, administrative employees, etc., excluding doctors and medical students) aged 20-63 years (mean age $=41.02 \pm 11.3$ years) $(81 \%$ women); none of them had been taking vitamin D supplement. Similar to our findings, there was no significant associations between serum 25(OH)D levels and age, sex, BMI, and sunscreen use; however, contrary to our study, serum 25(OH)D levels showed significant associations with educational level, and weekly hours of sun exposure (Gannagé-Yared et al., 2014). The two other studies looked at serum 25(OH)D levels and their determinants in samples of university students. In the first one (more recent) which surveyed a sample of 160 pharmacy private university students aged $21-24$ years (mean age $=23.24$ years), mean serum $25(\mathrm{OH}) \mathrm{D}$ level was found to be $16.80 \pm 5.85 \mathrm{ng} / \mathrm{ml}$ and prevalence of vitamin D deficiency $(\leq 20 \mathrm{ng} / \mathrm{ml})$ was revealed at $42.5 \%$ 
(Malaeb et al., 2017). In the second study, which was conducted among 381 private university students aged 18-30 years (mean age $=23.9 \pm 3.9$ years $)(53 \%$ men $)$, mean serum $25(\mathrm{OH}) \mathrm{D}$ level was reported to be $31 \pm 12.4 \mathrm{ng} / \mathrm{ml}$ and prevalence of vitamin D deficiency $(\leq 20 \mathrm{ng} / \mathrm{ml})$ was found to be $18.6 \%$; the study also showed, opposite to our study findings, that serum 25(OH)D level had a significant inverse correlation with BMI (Gannagé-Yared, Chedid, \& Halaby, 2010).

The lack of association between serum $25(\mathrm{OH}) \mathrm{D}$ levels and depressive symptoms in our study is comparable to that reported by several other studies from the US, Germany, Finland, Denmark, South Korea, and Japan. In a population-based sample of 3,916 American adults aged $\geq 20$ years, the adjusted odds of having moderate to severe depression (assessed using PHQ-9 score $\geq 10$ ) did not differ significantly between the highest and the lowest quartiles of serum $25(\mathrm{OH}) \mathrm{D}$ levels. In this sample, the age-adjusted prevalence of moderate-severe depression was found to be 5.3\% (Zhao, Ford, $\mathrm{Li}, \&$ Balluz, 2010). In another study which was conducted among a population-based sample of 6,331 German adults aged $18-79$ years (mean age $=46.8$ years), findings from both linear/ logistic regression analyses revealed no significant association between serum 25OHD levels and PHQ-9 score/ depression status (PHQ-9 score $\geq 10$ ) during wintertime after adjustment for confounders. In this sample, the mean 25(OH)D was $18.51 \mathrm{ng} / \mathrm{ml}$, mean PHQ-9 score was 4.1, and prevalence of depression (PHQ-9 score $\geq 10$ ) was $7.5 \%$ (Rabenberg et al., 2016). Although the adjusted odds of presence of current clinically relevant depressive symptoms (BDI score $\geq 10$ ) among individuals with serum $25(\mathrm{OH}) \mathrm{D}$ concentrations in the highest quartile was lower compared to those with serum $25(\mathrm{OH}) \mathrm{D}$ concentrations in the lowest quartile; yet it was statistically non-significant $(\mathrm{OR}=0.83,95 \% \mathrm{CI}: 0.69-1.01, \mathrm{p}=0.08)$ in a representative sample of 5,371 adult Finnish men and women aged 30-79 years (mean age $=50.4$ years) (Jääskeläinen et al., 2015). Findings from multiple linear/ logistic regression analyses of data from a Danish population-based adult sample aged 18-64 years $(\mathrm{n}=5,308)$ showed no significant association between serum 25(OH)D levels and self-reported depressive symptoms score/ depression score $>90$ th percentile for each sex, assessed using the Symptom Check List (SCL)-90-R, ( $\beta$-coefficient and 95\% CI per $10 \mathrm{nmol} / 1$ serum 25(OH)D were $0.00(-0.00$ to 0.01$)$ for depressive symptoms score) after adjustment for confounders (Husemoen et al., 2016). In a sample of 52,228 South Korean healthy employees aged 20-70 years (mean age $=38.4$ years, $86 \%$ men), serum $25 \mathrm{OHD}$ levels had no significant association with presence of depressive symptoms (defined by CES-D $\geq 21$ ) after adjustment for confounders. However, when using $25 \mathrm{OHD}$ as a categorical variable, the association with presence of depressive symptoms was evident only with the vitamin D deficient group $(<10 \mathrm{ng} / \mathrm{ml})$ (reference group: vitamin D sufficient $\geq 20 \mathrm{ng} / \mathrm{ml}$ ) (adjusted $\mathrm{OR}=1.158,95 \% \mathrm{CI}=1.003-1.336, \mathrm{p}=0.046)$. In this sample, $70.3 \%$ had serum $25(\mathrm{OH}) \mathrm{D}$ level $<20 \mathrm{ng} / \mathrm{ml}$ and $4.8 \%$ were found to be depressed (Shin, Jung, Kim, Kim, \& Lim, 2016). Findings from multivariate logistic regression analysis of data from a nationally representative sample of 15,695 South Korean adults aged $\geq 20$ years revealed no significant association between vitamin D status and self-reported current physician diagnosis of depression after controlling for confounders (Park, Yang, Won Park, \& Chung, 2016). In a sample of 368 public employees aged 21-67 years (mean age $=43.0$ years; $42 \%$ women) from Japan, the multivariate adjusted OR of having depressive symptoms (assessed using the Center for Epidemiologic Studies Depression Scale (CES-D); CES-D scores $\geq 16$ ) tended to decrease from the lowest (reference category) through the highest quartiles of serum 25(OH)D concentrations, yet it was statistically non-significant (Nanri et al., 2009).

On the other hand, our findings were in disagreement with others reported from the US, UK, Norway, Jordan, South Korea and Japan. Findings from logistic regression analysis of data of 12,594 American adults aged 20-90 years (mean age $=51.7$ years, $68 \%$ men), showed that the adjusted OR for having depression (assessed using the Center for Epidemiologic Studies Depression Scale (CES-D); CES-D scores $\geq 10$ ) for each $10 \mathrm{ng} / \mathrm{ml}$ increase in serum 25(OH)D levels was 0.92 (95\% CI: 0.87-0.97, $\mathrm{p}=0.02)$. In this sample, mean serum 25(OH)D level was found to be $30.9 \pm 12.4 \mathrm{ng} / \mathrm{ml}$ and $50.7 \%$ had serum $25(\mathrm{OH}) \mathrm{D}$ level $<30 \mathrm{ng} / \mathrm{ml}$ (Hoang et al., 2011). In another study which surveyed a sample of 7,970 American adults aged $15-39$ years (mean age=27.5 years, $46 \%$ men), the adjusted OR $(95 \% \mathrm{CI})$ for having depression (assessed using the Diagnostic Interview Schedule (DIS)) among vitamin D deficient $(<20 \mathrm{ng} / \mathrm{ml})$, compared to vitamin D sufficient $(>30 \mathrm{ng} / \mathrm{ml})$ was $1.85(0.90-3.81, \mathrm{p}=0.021)$. However, the adjusted OR for having depression among vitamin D insufficient (20-30 ng/ml) compared to vitamin D sufficient was not statistically significant (Ganji, Milone, Cody, McCarty, \& Wang, 2010). Findings from a study which looked at data of 7,401 British cohort aged 45 years revealed significant dose-dependent inverse association between serum 25(OH)D level and depression (assessed using Clinical Interview Schedule Revised (CIS-R)). The adjusted odds of having depression among participants with serum 25(OH)D level between 75-99.9 were found to be significantly lower than that of those with serum $25(\mathrm{OH}) \mathrm{D}$ levels $<25 \mathrm{nmol} / \mathrm{l}(\mathrm{OR}=0.59$; 95\%CI: 0.41-0.86; $\mathrm{p}=0.001$ ) (Maddock, Berry, Geoffroy, Power, \& Hyppönen, 2013). The adjusted odds ratio for depression (Hopkins Symptoms Check List 10 (SCL-10) scores $\geq 1.85$ ) in the highest serum 25(OH)D quartile was found to be 
significantly lower compared with the lowest serum $25(\mathrm{OH}) \mathrm{D}$ quartile) in a population-based sample of 10,086 adults aged 30-87 years from Northern Norway (Kjærgaard, Joakimsen, \& Jorde, 2011). In a national population based sample of 4,002 adults aged $\geq 25$ years from Jordan, the adjusted OR for having depression (assessed using depression subscale of the Depression Anxiety Stress Scales (DASS21); DASS-D score $\geq 14$ ) among those with serum $25 \mathrm{OHD}$ level $<30 \mathrm{ng} / \mathrm{ml}$ compared to those with serum $25 \mathrm{OHD}$ level $\geq 30 \mathrm{ng} / \mathrm{ml}$ was 1.38 ( $\mathrm{p}=0.00)$. In this sample 31.8\% reported having moderate to extremely severe depression (Jaddou et al., 2012). The adjusted odds of depression (assessed using a self-reported single question) among the vitamin D sufficient group ( $\geq 20 \mathrm{ng} / \mathrm{ml}$ ) compared to the insufficient group $(<20 \mathrm{ng} / \mathrm{ml})$ was significantly lower $(\mathrm{OR}=0.72,95 \% \mathrm{CI}: 0.53-0.97 ; \mathrm{p}=0.032)$ in a nationally representative sample of 3,570 adults from South Korea aged $\geq 20$ years (mean age $=43.3$ years, $47 \%$ men) (Chung, Cho, Choi, \& Shin, 2014). In a sample of 1,786 Japanese healthy employees aged $19-69$ years (91\% men), the adjusted ORs $(95 \% \mathrm{CI})$ for presence of depressive symptoms (assessed using the Center for Epidemiologic Studies Depression Scale (CES-D)) for the highest $(\geq 30 \mathrm{ng} / \mathrm{ml})$ category of 25(OH)D versus the lowest $(<20 \mathrm{ng} / \mathrm{ml})$ was $0.66(0.41,1.06)(\mathrm{p}=0.01)$. The association between serum 25(OH)D concentration and depressive symptoms appeared to be inverse linear in fully adjusted models (Mizoue et al., 2015).

The lack of significant association between serum 25(OH)D levels and severity of depressive symptoms in our study can be accounted for by several possible explanations. 1) We had low prevalence rates of vitamin $D$ deficiency ( $\leq 10 \mathrm{ng} / \mathrm{ml}: 4.6 \%$; $\leq 20 \mathrm{ng} / \mathrm{ml}: 31.9 \%$ ) and moderate-severe depression (PHQ-9 $\geq 10: 5.4 \%$ ) in our sample. Though it is possible that the actual prevalence of depression in our sample is $5.4 \%$, it could also be that members of the target population with moderate-severe depression did not participate in the study. Should the study findings (5.4\% of the sample had moderate-severe depression) be accurate, then low prevalence rate of depression in our sample is quite likely one important factor accounting for lack of association between serum 25(OH)D levels and depressive symptoms. 2) The association between vitamin D status and depression is more likely to be evident when vitamin D deficient or insufficient (vs. sufficient) (Parker, Brotchie, \& Graham, 2017), and serum vitamin D levels may not have a strong relationship with depressive symptoms when the levels are optimal or suboptimal (Shin et al., 2016). 3) The concept of a threshold for an effect of serum 25(OH)D level on depression may underlie the lack of association in our study. When examining association between serum $25(\mathrm{OH}) \mathrm{D}$ level at age 45 years and depression at age 50 years, analyses revealed non-linear significant association, after adjustment for confounders. Participants with serum 25(OH)D levels between 50 and $85 \mathrm{nmol} / \mathrm{l}$ at baseline (45 years) had significantly lower risk of subsequent depression at 50 years compared to those with lower or higher serum 25(OH)D concentrations (Maddock et al., 2013). 4) The effect of vitamin D supplementation on depressive symptoms was small and statistically insignificant in trials of non-clinically depressed participants (Shaffer et al., 2014). 5) Differences in methodological approaches such as differences in characteristics of study population, season of blood collection, assays used for measurement of serum 25(OH)D levels, reference categories of vitamin D concentration, instruments used for assessment of depression (self-reported symptom scale versus diagnostic interviews), conceptualization of depression (depressive symptoms continuum or "caseness" of depression), regression techniques/ types, and covariates adjusted for in regression analyses, were pointed out by many investigators as possible explanations for inconsistent results (Anglin et al., 2013; Ju et al., 2013; Parker et al., 2017). 6) The heterogeneity of depression may justify why low serum 25(OH)D levels may be relevant only in specific subgroups of depressed patients (Milaneschi et al., 2014).

\subsection{Study Strengths and Limitations}

Our study is the first in the Arab region to explore the relationship between serum 25(OH)D levels and depressive symptoms in healthy employees aged 18-65 years, and the second one to examine this association among healthy adults (the first one is that conducted by Jaddou et al., 2012). Compared to the study done by Jaddou et al. (2012) targeting a population-based sample of 4,002 Jordanian adults aged $\geq 25$ years, we took into account adjustment for important covariates known to influence depression such as income, family history of depression, and stressful life events. We adopted validated measures of serum 25(OH)D levels and depressive symptoms.

Alternatively, our study bears several limitations. Despite a relatively good sample size, the low and narrow range of PHQ-9 scores may have reduced the ability to detect an association between $25(\mathrm{OH}) \mathrm{D}$ and depressive symptoms. Alternatively, the low prevalence rate of moderate-severe depression $(5.4 \%)$ in the sample did not allow us to stratify the data. It is quite likely that cases with moderate-severe depressive symptoms were under-represented in our sample compared to background population (Karam, et al., 2008). Though the assay that we used to measure serum $25(\mathrm{OH}) \mathrm{D}$ is deemed suitable, it is possible that different $25(\mathrm{OH}) \mathrm{D}$ values could have been obtained should we had used another assay given the inter-assay differences in measurement of $25(\mathrm{OH}) \mathrm{D}$ (Fuleihan et al., 2015). Data on depressive symptoms and multiple other variables were self-reported; hence it is probable that some data may not be accurate. Though we adjusted for a wide sum of potential confounders, we 
cannot exclude others such as diet quality. Collin et al. (2017) reported that a slightly low 25(OH)D level may not have a negative impact on depressive symptoms if the overall dietary quality is high. Our study targeted employees at a private university; hence, our results cannot be generalized to the general adult population in Lebanon.

In conclusion, we did not find any significant independent association between serum 25(OH)D levels and severity of depressive symptoms in a sample of Lebanese employees of a private academic institution. There remains a need for studies to further explore this association in a representative large sample of Lebanese adults, and figure out clinical significance of this association, if any. Prospective studies would provide indications as to whether low vitamin $\mathrm{D}$ level is a predecessor or a consequence of depression.

\section{Authors' Disclosure}

The authors declare that they have no conflict of interest.

\section{References}

Abdollahzadeh, R., Fard, M. S., Rahmani, F., Moloudi, K., Kalani, B. S., \& Azarnezhad, A. (2016). Predisposing role of vitamin D receptor (VDR) polymorphisms in the development of multiple sclerosis: A case-control study. Journal of the Neurological Science, 367, 148-151. https://doi.org/10.1016/j.jns.2016.05.053

Anglin, R. E., Samaan, Z., Walter, S. D., \& McDonald, S. D. (2013). Vitamin D deficiency and depression in adults: systematic review and meta-analysis. The British Journal of Psychiatry, 202, 100-107. https://doi.org/10.1192/bjp.bp.111.106666

Arabi, A., El Rassi, R., \& El-Hajj Fuleihan, G. (2010). Hypovitaminosis D in developing countries-prevalence, risk factors and outcomes. Nature Reviews Endocrinology, 6(10), 550-561. https://doi.org/10.1038/nrendo.2010.146

Bassil, D., Rahme, M., Hoteit, M., \& Fuleihan, G. (2013). Hypovitaminosis D in the Middle East and North Africa: Prevalence, risk factors and impact on outcomes. Dermato-endocrinology, 5(2), 274-298. https://doi.org/10.4161/derm.25111

Booth, M. (2000). Assessment of physical activity: an international perspective. Research Quarterly for Exercise and Sport, 71, S114-S120.

Centers for Disease Control and Prevention (CDC). (2007). National Health and Nutrition Examination Survey (NHANES): anthropometry procedures manual. Retrieved from https://www.cdc.gov/nchs/data/nhanes/nhanes_07_08/manual_an.pdf

Charara, R., Forouzanfar, M., Naghavi, M., Moradi-Lakeh, M., Afshin, A., Vos, T., ... Mokdad, A. (2017). The Burden of Mental Disorders in the Eastern Mediterranean Region, 1990-2013. PLoS ONE, 12(1), e0169575. https://doi.org/10.1371/journal.pone.0169575

Chung, H.K., Cho, Y., Choi, S., \& Shin, M.J. (2014). The Association between Serum 25-Hydroxyvitamin D Concentrations and Depressive Symptoms in Korean Adults: Findings from the Fifth Korea National Health $\begin{array}{llllll}\text { and Nutrition Examination Survey 2010. PLoS ONE, 9(6), e99185. } & \text {. }\end{array}$ https://doi.org/10.1371/journal.pone.0099185

Collin, C., Assmann, K.E., Deschasaux, M., Andreeva, V.A., Lemogne, C., Charnaux, N., ... Kesse-Guyot, E. (2017). Plasma vitamin D status and recurrent depressive symptoms in the French SU.VI.MAX cohort. European Journal of Nutrition, 56(7), 2289-2298. https://doi.org/10.1007/s00394-016-1269-y

El Hayek, J., Pham, T.T., Finch, T., Hazell, T.J., Vanstone, C., \& Weiler, H. (2014). Validity and Reproducibility of a Short Food Frequency Questionnaire in Assessing Calcium and Vitamin D Intake in Canadian Preschoolers. EC Nutrition, 1 (1), 9-19.

Eyles, D.W., Liu, P.Y., Josh, P., \& Cui, X. (2014). Intracellular distribution of the vitamin D receptor in the brain: comparison with classic target tissues and redistribution with development. Neuroscience, 268, 1-9. https://doi.org/10.1016/j.neuroscience.2014.02.042

Eyles, D. W., Smith, S., Kinobe, R., Hewison, M., \& McGrath. J. J. (2005). Distribution of the vitamin D receptor and 1 alpha-hydroxylase in human brain. Journal of Chemical Neuroanatomy, 29(1), 21-30.

Fuleihan, G., Bouillon, R., Clarke, B., Chakhtoura, M., Cooper, C., McClung, M., \& Singh, R. J. (2015). Serum 25-Hydroxyvitamin D Levels: Variability, Knowledge Gaps, and the Concept of a Desirable Range. Journal of Bone and Mineral Research, 30(7), 1119-1133. https://doi.org/10.1002/jbmr.2536

Ganji, V., Milone, C., Cody, M. M., McCarty, F., \& Wang, Y. T. (2010). Serum vitamin D concentrations are 
related to depression in young adult US population: the Third National Health and Nutrition Examination Survey. International Archives of Medicine, 3, 29. https://doi.org/10.1186/1755-7682-3-29

Gannagé-Yared, M. H., Chedid, R., \& Halaby, G. (2010). [Vitamin D status in Lebanese university students]. Lebanese Medical Journal, 58(4), 191-194.

Gannagé-Yared, M. H., Helou, E., Zaraket, V., Abi Akl, S., Antonios, L., Moussalli, M. L., \& Wakim, S. (2014). Serum 25 hydroxyvitamin D in employees of a Middle Eastern university hospital. Journal of Endocrinological Investigation, 37(6), 541-546. https://doi.org/10.1007/s40618-014-0061-1

Government of Canada. (2017). Canadian Nutrient File (CNF). Retrieved from https://food-nutrition.canada.ca/cnf-fce/index-eng.jsp

Hoang, M. T., Defina, L. F., Willis, B. L., Leonard, D. S., Weiner, M. F., \& Brown, E. S. (2011). Association between low serum 25-hydroxyvitamin D and depression in a large sample of healthy adults: the Cooper Center longitudinal study. Mayo Clinic Proceedings, 86(11), 1050-1055. https://doi.org/10.4065/mcp.2011.0208

Holick, M. F, Binkley N. C, Bischoff-Ferrari, H. A, Gordon, C. M., Hanley, D. A., Heaney, R. P., et al. (2011). Evaluation, treatment, and prevention of vitamin D deficiency: an Endocrine Society clinical practice guideline. The Journal of Clinical Endocrinology \& Metabolism, 96(7), 1911-1930.

Holick, M. F., \& Chen, T. C. (2008). Vitamin D deficiency: A worldwide problem with health consequences. The American Journal of Clinical Nutrition, 87(4), 1080S-1086S.

Husemoen, L. L., Ebstrup, J. F., Mortensen, E. L., Schwarz, P., Skaaby, T., Thuesen, B. H., ... Linneberg, A. (2016). Serum 25-hydroxyvitamin D and self-reported mental health status in adult Danes. European Journal of Clinical Nutrition, 70(1), 78-84. https://doi.org/10.1038/ejen.2015.129

Jääskeläinen, T., Knekt, P., Suvisaari, J., Männistö, S., Partonen, T., Sääksjärvi, ... Lindfors, O. (2015). Higher serum 25-hydroxyvitamin D concentrations are related to a reduced risk of depression. The British Journal of Nutrition, 113(9), 1418-1426. https://doi.org/10.1017/S0007114515000689

Jaddou, H. Y., Batieha, A. M., Khader, Y. S., Kanaan, S. H., El-Khateeb, M. S., \& Ajlouni, K. M. (2012). Depression is associated with low levels of 25-hydroxyvitamin D among Jordanian adults: Results from a national population survey. European Archives of Psychiatry and Clinical Neuroscience, 262(4), 321-327. https://doi.org/10.1007/s00406-011-0265-8

Ju, S. Y., Lee, Y. J., \& Jeong, S. N. (2013). Serum 25-hydroxyvitamin D levels and the risk of depression: a systematic review and meta-analysis. The Journal of Nutrition, Health \& Aging, 17(5), 447-455. https://doi.org/10.1007/s12603-012-0418-0

Karam, E. G., Mneimneh, Z. N., Dimassi, H., Fayyad, J. A., Karam, A. N., Nasser, S. C., Chatterji, S., \& Kessler, R. C. (2008). Lifetime Prevalence of Mental Disorders in Lebanon: First Onset, Treatment, and Exposure to War. PLoS Medicine, 5(4), e61. https://doi.org/10.1371/journal.pmed.0050061

Kjærgaard, M., Joakimsen, R., \& Jorde, R. (2011). Low serum 25-hydroxyvitamin D levels are associated with depression in an adult Norwegian population. Psychiatry Research, 190(2-3), 221-225. https://doi.org/10.1016/j.psychres.2011.06.024

Kroenke K, Spitzer R, Williams J, Löwe B (2010) The Patient Health Questionnaire somatic, anxiety, and depressive symptom scales: a systematic review. General Hospital Psychiatry, 32, 345-359. https://doi.org/10.1016/j.genhosppsych.2010.03.006

Kuningas, M., Mooijaart, S.P., Jolles, J., Slagboom, P.E., Westendorp, R.G., \& van Heemst, D. (2009). VDR gene variants associate with cognitive function and depressive symptoms in old age. Neurobiology of Aging, 30(3), 466-473.

Li, G., Mbuagbaw, L., Samaan, Z., Falavigna, M., Zhang, S., Adachi, J.D., Cheng, J.,... Thabane, L. (2014). Efficacy of Vitamin D Supplementation in Depression in Adults: A Systematic Review. The Journal of Clinical Endocrinology and Metabolism, 99(3), 757-767. https://doi.org/10.1210/jc.2013-3450

Maddock, J., Berry, D.J., Geoffroy, M.C., Power, C., \& Hyppönen, E. (2013). Vitamin D and common mental disorders in mid-life: cross-sectional and prospective findings. Clinical Nutrition, 32(5), 758-764. https://doi.org/10.1016/j.clnu.2013.01.006

Malaeb, D., Hallit, S., \& Salameh, P. (2017). Assessment of vitamin D levels, awareness among Lebanese 
pharmacy students, and impact of pharmacist counseling. Journal of Epidemiology and Global Health, 7(1),55-62. https://doi.org/10.1016/j.jegh.2016.09.001

Milaneschi, Y., Hoogendijk, W., Lips, P., Heijboer, A. C., Schoevers, R., van Hemert, A. M.,... Penninx, B. W. (2014). The association between low vitamin D and depressive disorders. Molecular Psychiatry, 19(4), 444-451. https://doi.org/10.1038/mp.2013.36

Mizoue, T., Kochi, T., Akter, S., Eguchi, M., Kurotani, K., Tsuruoka, H., ... Nanri, A. (2015). Low serum 25-hydroxyvitamin D concentrations are associated with increased likelihood of having depressive symptoms among Japanese workers. The Journal of Nutrition, 145(3), 541-546. https://doi.org/10.3945/jn.114.204115

Mokdad, A. (2017). The burden of mental disorders in the Eastern Mediterranean region, 1990-2015: findings from the global burden of disease 2015 study. International Journal of Public Health, 1-13. https://doi.org/10.1007/s00038-017-1006-1

Nanri, A., Mizoue, T., Matsushita, Y., Poudel-Tandukar, K., Sato, M., Ohta, M., \& Mishima, N. (2009). Association between serum 25-hydroxyvitamin D and depressive symptoms in Japanese: analysis by survey season. European Journal of Clinical Nutrition, 63(12), 1444-1447. https://doi.org/10.1038/ejcn.2009.96

Park, J.I., Yang , J.C., Won Park, T., \& Chung, S. K. (2016). Is serum 25-hydroxyvitamin D associated with depressive symptoms and suicidal ideation in Korean adults? International Journal of Psychiatry in Medicine, 51(1), 31-46. https://doi.org/10.1177/0091217415621042

Parker, G. B., Brotchie, H., \& Graham, R. K. (2017). Vitamin D and depression. Journal of Affective Disorders, 208, 56-61. https://doi.org/10.1016/j.jad.2016.08.082

Pellett, P., \& Shadarevian, S. (2013). Food composition tables for use in the Middle East, $3^{\text {rd }}$ edition. Beirut: American University of Beirut.

Pfizer. (n,d,). Instruction Manual: Instructions for Patient Health Questionnaire (PHQ) and GAD-7 Measures. Retrieved from https://phqscreeners.pfizer.edrupalgardens.com/sites/g/files/g10016261/f/201412/instructions.pdf

Rabenberg, M., Harisch, C., Rieckmann, N., Buttery, A. K., Mensink, G. B. M., \& Busch, M. A. (2016). Association between vitamin and depressive symptoms varies by season: Results from the German Health Interview and Examination Survey for Adults (DEGS1). Journal of Affective Disorders, 204, 92-98. https://doi.org/10.1016/j.jad.2016.06.034

Ross, A. C., Taylor, C. L., Yaktine, A. L., \& Del Valle, H. B. (2011). Dietary Reference Intakes for Calcium and Vitamin D. Washington, DC: National Academies Press.

Shaffer, J. A., Edmondson, D., Wasson, L. T., Falzon, L., Homma, K., Ezeokoli, N., ... Davidson, K. W. (2014). Vitamin D supplementation for depressive symptoms: a systematic review and meta-analysis of randomized controlled trials. Psychosomatic Medicine, 76(3), 190-196. https://doi.org/10.1097/PSY.0000000000000044

Shaikh, F., Baig, S., \& Jamal, Q. (2016). Do VDR Gene Polymorphisms Contribute to Breast Cancer? Asian Pacific Journal of Cancer Prevention, 17(2), 479-483.

Shin, Y. C., Jung, C. H., Kim, H. J., Kim, E. J., \& Lim, S. W. (2016). The associations among vitamin D deficiency, C-reactive protein, and depressive symptoms. Journal of Psychosomatic Research, 90, 98-104. https://doi.org/10.1016/j.jpsychores.2016.10.001

Spedding, S. (2014). Vitamin D and Depression: A Systematic Review and Meta-Analysis Comparing Studies with and without Biological Flaws. Nutrients, 6(4), 1501-1518. https://doi.org/10.3390/nu6041501

WHO Expert Consultation. (2004). Appropriate body-mass index for Asian populations and its implications for policy and intervention strategies. Lancet, 363, 157-163.

World Health Organization. (2017). Depression and Other Common Mental Disorders: Global Health Estimates. Geneva: World Health Organization. Retrieved from http://www.who.int/iris/handle/10665/254610

Yu, F., Cui, L. L., Li, X., Wang, C. J., Ba, Y., Wang, L., ... Li, W. J. (2016). The genetic polymorphisms in vitamin D receptor and the risk of type 2 diabetes mellitus: an updated meta-analysis. Asia Pacific Journal of Clinical Nutrition, 25(3), 614-624. https://doi.org/10.6133/apjcn.092015.12

Zhao, G., Ford, E. S., Li, C., \& Balluz, L. S. (2010). No associations between serum concentrations of 25-hydroxyvitamin D and parathyroid hormone and depression among US adults. The British Journal of Nutrition, 104(11), 1696-1702. https://doi.org/10.1017/S0007114510002588 


\section{Copyrights}

Copyright for this article is retained by the author(s), with first publication rights granted to the journal.

This is an open-access article distributed under the terms and conditions of the Creative Commons Attribution license (http://creativecommons.org/licenses/by/4.0/). 